DOI: http://dx.doi.org/10.22198/rys.2018.73.a933

Artículos

\title{
De beatas y beaterios jesuitas de la provincia del Paraguay, siglos XVII-XVIII
}

\begin{abstract}
Of Jesuit beatas and beaterios in the Province of Paraguay,
\end{abstract} 17 th-18th centuries

\author{
Carlos A. Page* \\ http://orcid.org/0000-0003-4708-5243
}

Resumen: en las Constituciones de la Compañía de Jesús se estableció que no se podrían incorporar mujeres a su comunidad. Sin embargo, en todo el mundo se crearon congregaciones femeninas independientes que siguieron las reglas jesuitas. Aquí se dan algunos ejemplos para alcanzar el objetivo del artículo, que es indagar sobre las beatas que fueron destacadas en la documentación de los jesuitas de la provincia del Paraguay; se admiten las dificultades que implica no contar con otras fuentes. De esta manera se dan a conocer algunas mujeres prácticamente desconocidas en la historiografía religiosa y, a su vez, el interés en sus ámbitos, los beaterios, que permiten contribuir al conocimiento del modo de vida espiritual que llevaban. Solo se mencionó uno de éstos en los inventarios de las temporalidades de toda la provincia, por lo que se pretende indagar sobre el origen, la descripción y el destino del edificio.

* Investigador independiente en el Centro de Investigaciones y Estudios sobre Cultura y Sociedad-Consejo Nacional de Investigaciones Científicas y Técnicas y Universidad Nacional de Córdoba, Argentina. Av. Valparaíso s/n, Ciudad Universitaria-Córdoba, C. P. 5000, Argentina. Correo electrónico: capage1@hotmail.com 
Palabras clave: mujeres en la religión; religiosidad; beatas; beaterios; Compañía de Jesús-historia; provincia jesuítica del Paraguay; casas de ejercicios.

Abstract: in Society of Jesus' Constitutions it was established that women could not join this community. However, independent congregations of women that followed Jesuit rules were created worldwide. Here, some examples are given in order to achieve the article's aim, which is to investigate about the beatas featured in the Jesuit documentation of the Province of Paraguay. Difficulties arising from the fact that other sources are not available are admitted. In this sense, some women virtually unknown in religious historiography are now revealed, and, in turn, an interest in their environment, beaterios, has grown, this contributing to the understanding of their way of spiritual life. Only one of these was mentioned in the inventories of Temporalities throughout the province, which is why the aim is to inquire about the origin, description and fate of the building.

Keywords: women in religion; religiosity; beatas; beaterios; Society of Jesus-history; Jesuit Province of Paraguay; retreat houses.

Recibido el 1 de junio de 2017. Aceptado el 12 de octubre de 2017.

\section{Introducción y antecedentes}

El tema de las jesuitisas o jesuitesas alcanzó relevancia a partir de las investigaciones del padre Anton Huonder (1932), a principios del siglo XIX, quien dedicó varias páginas a las relaciones de los jesuitas con el "mundo femenino". Se acrecentó el interés con la publicación de las cartas de san Ignacio con mujeres, realizada por el jesuita alemán Hugo Rahner (1956), quien desbarató la fama tendenciosa de misoginia ignaciana. A partir de allí se multiplicaron las investigacio- 
nes en torno al rol de la mujer en la Compañía de Jesús y, sobre todo, en relación con san Ignacio, ${ }^{1}$ debate que se prolongó hasta la actualidad en forma cuasi sensacionalista (Ambrona 2017).

Aquí se hará un recorrido general sobre el tema, para introducirse en la vida de algunas mujeres, que fue documentada por los jesuitas, quienes eligieron esta opción devocional en la provincia jesuítica del Paraguay (1607-1767). Esos personajes se vinculan con los ámbitos donde ejercieron sus ministerios; se trata de mujeres en la Colonia, cuando ocupaban un papel importante en la religiosidad barroca pero que, pese a ello, eran descalificadas y pocas se atrevían a enfrentarse al hombre en cuestiones teológicas, como lo hizo sor Juana Inés de la Cruz, quien cuestionó nada menos que al jesuita Antonio Vieira (Burrieza 2005, 86).

Estas mujeres, relacionadas con los jesuitas, fueron beatas y residían en casas propias, pero con el tiempo se reubicaron en un edificio adecuado para sus prácticas, que se denominaba "casa de beatas", "beaterios" o "emparedamientos", ${ }^{2}$ como se llamaban antiguamente, sin que fueran sinónimos. Estos sitios eran viviendas de mujeres piadosas "que se recogían a la vida común con fines ascéticos y caritativos, regidas por normas parecidas a las de religiosas, pero sin votos religiosos propiamente dichos" (Ruiz 2001, 920). Por lo general eran viudas o doncellas que pretendían cambiar su vida, y la religión les ofrecía otras alternativas, es decir, "vías donde dar salida a sus frustraciones, sublimar una vida matrimonial poco compensadora o, simplemente, desarrollar de manera más singular sus apetencias espirituales" (Pons 1991, 75).

Los jesuitas no contaron con una rama femenina de la orden, como las tuvieron otras, pero sí patrocinaron y fueron guías espirituales de muchos institutos religiosos femeninos. Algunos adoptaron las reglas, o se inspiraron en los textos normativos de la Compañía de Jesús, y los jesuitas intervenían de diversas formas.

Hay una bibliografía completa al respecto en Soto Artuñedo (1997, 299-318).

2 Este término se refiere al voto femenino de tinieblas, es decir, a estar encerradas entre paredes y que fue un castigo medieval tradicional en Europa hasta 1693, cuando el sínodo del obispo Ayala lo prohibió. Se podía aplicar a ciertas mujeres por sus faltas y delitos, o ser voluntario, con autorización de familiares para adoptar la vida penitente o beguina, que implica ser espiritual pero no religiosa, vivir entre mujeres pero no ser monja, rezar y trabajar, pero no en un monasterio (Rivera 2005, 114). 
El origen de la participación de la mujer en la Compañía de Jesús -como explica el padre Escalera- se remonta a 1545 en Roma, cuando tres mujeres solicitaron vivir en obediencia a Ignacio. Por presión de una de ellas, el papa Paulo III, el mismo que aprobó la creación del instituto en 1540, admitió su petición y se lo impuso al general encargándole la administración de la Casa de Santa Marta, ${ }^{3}$ dedicada a paliar la prostitución. Pero al año siguiente, con aprobación del pontífice, san Ignacio relevó a las votantes de su compromiso, y en 1547 la bula Licet debitum anuló la obligación, y proclamó luego en las constituciones la exención de los jesuitas de dirigir en forma permanente a una comunidad de religiosas. Por tanto, la experiencia sirvió de antecedente para disuadir definitivamente cualquier otra petición futura que tendiera a crear una rama femenina. Hubo varios intentos, y con ellos vendrían excepciones, como la única otorgada a la princesa doña Juana de Austria a quien los jesuitas le concedieron, en 1554, "votos simples" (pobreza, castidad y obediencia) que profesan ellos, luego de cumplir dos años en el noviciado. De tal manera que fue hasta el siglo XX cuando los historiadores mencionaron los votos privados y secretos de su ingreso a la Compañía de Jesús. Fue la única jesuita de la historia y, en agradecimiento, aportó 3 mil ducados para la fundación del Colegio de Valladolid (Martínez de la Escalera 2004, 369-384).

Las solicitudes aumentaron, de forma notable en todo el mundo, y de una manera u otra se crearon congregaciones que siguieron las reglas de la Compañía de Jesús, pero sin depender de ésta y, en muchos casos, con la ayuda espiritual de los jesuitas. Así se formaron los beaterios independientes de la orden.

En diversas provincias de Europa y América se crearon varias fundaciones, como la del Paraguay. Una de las primeras, si no es que la original, Casa de Beatas de la Compañía, fue la de Filipinas, creada en 1684; tuvo la particularidad de que su iniciadora, Ignacia del Espíritu Santo, la instituyó para jóvenes indígenas que no podían ingresar a las comunidades religiosas, así ayudó a los jesuitas en los retiros es-

3 San Ignacio pudo comprar esta casa con ayuda de bienhechores, y era administrada por la asociación piadosa "Compañía de la Gracia”, aprobada por bula de Paulo II en 1543. San Ignacio fue su director espiritual y en siete años pasaron por ella más de 300 mujeres, y dejó la dirección en 1548, cuando su funcionamiento quedó consolidado. 
pirituales para mujeres. Llegaron a contar con casa propia, donde comenzaron a hospedar a mujeres que deseaban vivir retiradas, y hasta consiguieron que el obispo aprobara sus reglas, en 1732. En México, los padres jesuitas, Feliciano Pimentel, construyó una casa de recogimiento en Guadalajara, y Antonio de Herdoñana hizo lo propio con doncellas indígenas en un lugar contiguo al Colegio de San Gregorio, con reglas similares a las de los jesuitas. Su función fue aprobada por la corte, en 1754, con el nombre de Real Colegio de Indias Mexicanas de Nuestra Señora de Guadalupe (Ruiz 2001, 920).

Había beatas de toda condición social, como indígenas y también de castas pero, sobre todo, de cierta fortuna. De todas formas vivían de limosnas y caridad, en estado de oración y semirecluidas. En cuanto a sus bienes, después de su muerte por lo general se los donaban a los jesuitas. ${ }^{4}$ Supieron tener discípulas, parientas o no, pero siempre manteniendo la fama de santidad, acompañada de la mortificación y penitencias que alentaba su director espiritual.

La condición de beatas traía algunas ventajas para sus familias, ya que si tuvieran que ingresar a un monasterio lo debían hacer con una dote. En este caso no era necesario, y además contaban con el patrocinio de familiares y vecinos, e incluso de algunos funcionarios del gobierno que promovieron la creación de casas de aislamiento.

\section{Beatas de la provincia jesuítica del Paraguay}

La Compañía de Jesús en América del Sur se organizó en torno a la provincia del Perú, desde 1568. Tuvo un desprendimiento ordenado por el general Acuaviva, en 1604, que se cumplió en forma efectiva tres años después con la creación de la provincia del Paraguay. Abarcó las gobernaciones de Buenos Aires y Paraguay hasta 1617, cuando ambas se dividen, la de Tucumán, Santa Cruz y la capitanía general de Chile, durante las primeras décadas. Esta división político-administrativa equivalía a parte de su correlativa eclesiástica, que giraba

4 Tal es el caso, entre muchas, de la noble española doña Catalina de Mendoza, conocida como la Marquesa santa, quien dejó sus bienes a la Compañía, haciendo votos de obediencia a san Francisco de Borja y a los generales sucesivos (Martínez de la Escalera 2004, 374). 
en torno al arzobispado de Lima sobre el obispado de Chile (1561), del Tucumán (1582), de Santa Cruz de la Sierra (1605), del Río de la Plata (1609) del que luego se desprendió el de Asunción (1620).

Los antiguos historiadores, padres de la Compañía de Jesús del Paraguay, no mencionaron a las beatas; no lo hizo el padre Del Techo, aunque Lozano dejó clara la vinculación del padre Diego de Torres con las mujeres, en su primera visita a Asunción, cuando conoció a la madre Francisca Jesusa Pérez de Bocanegra, quien tenía a su cargo la Casa de Doncellas Recogidas de esa ciudad. ${ }^{5}$ La matrona se dedicó al servicio de nuestra señora del Rosario, con hábito de beata de santo Domingo. Criaba en su casa a medio centenar de doncellas pobres, les inculcaba la vida en recogimiento y el temor a Dios, y frecuentaba la iglesia del colegio de los jesuitas. El padre Torres no solo impartió pláticas espirituales, sino que consiguió limosnas para que la casa se convirtiera en monasterio religioso. Al morir, la anciana fue enterrada en la iglesia del colegio (Lozano 1755, 246).

Al extender la historia de Charlevoix y publicarla en latín, en 1779, el padre Muriel mencionó los cotiguazú de las reducciones guaraníticas y las comparó con los beaterios, aunque aclara que en realidad eran muy diferentes. Cuenta que:

Hay en cada pueblo dos cárceles: una de hombres, otra de mujeres. La de hombres está en una esquina de la plaza, cerca de la iglesia; la de mujeres en una casa separada, que se llama Casa de Recogidas, y en idioma guaraní Cotiguazú. Las recogidas no están encarceladas, sino libres, a la manera de las que vulgarmente se llaman Beatas. Nunca salen sino en comunidad y con su Directora.

Pero aclara: "Allí se ponen también las delincuentes en prisión o libres" $(1919,542)$.

El padre Hernández tradujo al castellano la obra de Muriel, pero también publicó la relación del padre Cardiel, escrita en 1770, y en referencia a este domicilio, es casi una reproducción de lo que escribe después Muriel. De tal modo que Cardiel solo amplió: "Allí se ponen,

5 La casa fue promovida por el obispo fray Martín Ignacio de Loyola, sobrino del santo, con la ayuda económica del gobernador Hernandarias y su esposa. 
con grillos ó sin ellos, las mujeres delincuentes". Además que: "A las mujeres se les azota en las espaldas y como en oculto, en la casa de las recogidas, por mano de otra mujer, que ordinariamente es superiora suya" (Hernández 1913, 577). Es decir, era el mismo edificio para dos destinos, se diría que casi opuestos.

Mientras tanto, en las ciudades españolas rioplatenses tardaron en crearse monasterios de monjas. Solo los hubo en Córdoba, el de Santa Catalina de Siena (1613) y el de San José de Carmelitas Descalzas (1628), en tanto que en Buenos Aires se crearon a mediados del siglo siguiente: Santa Catalina de Siena (1745) y Nuestra Señora del Pilar (1749). Por lo que las mujeres no tenían mayores posibilidades de dedicar su tiempo a la vida espiritual si no fuera como beatas.

Hay algunas noticias, como la del general Juan Pablo Oliva, del 23 de setiembre de 1679, cuando expresa que en Buenos Aires y "otros puntos", hacía unos

cuarenta años que se ha introducido un género de Beatas que llaman de la Compañía; hacen voto de castidad, visten sotana negra con toca y manto de anascote, viven en sus casas con grande ejemplo y comulgan dos veces a la semana en nuestra iglesia y son las personas más nobles y ejemplares de la ciudad (Furlong 1944, 81).

Las cartas anuas brindan noticias complementarias en lo que se refiere a los "otros puntos", pues expresan que en Santiago del Estero se comenzó con un beaterio en 1640, e informan que: "Hay allí un gran número de vírgenes consagradas a Dios, que viven fuera del claustro, y que se llaman beatas. No son inferiores a las monjas claustradas, tanto por su fervor en la virtud, como por su modestia y recogimiento" (Salinas et al. 2008, 144). Este antecedente sería importante para la ciudad en años venideros, porque de ahí surgiría una figura emblemática.

En los mismos informes remitidos a Roma, del periodo 16821688 se agrega la ciudad de La Rioja, donde:

algunas señoras piadosas y nobles matronas habiendo hecho voto de castidad y alejado de sí todas las vanidades mundanas, hanse 
consagrado al estado de perfección gracias a nuestra ayuda, y son muy dadas a los ayunos y penitencias, como también a la oración. Asiduamente están en nuestra iglesia y frecuentemente reciben la sagrada Eucaristía. ${ }^{6}$

En las cartas anuas no se brindaban necrológicas que no fueran de jesuitas, sin embargo se mencionan algunos personajes, a veces indígenas como el artista Esteban (1649), había esclavas africanas como la catequista Catalina Álvarez (1730-1735), y también se encontraban mujeres españolas. De las muchas beatas que había, aquí se hará referencia solo a las mencionadas en la documentación jesuítica. Alrededor de la misma época, las cartas anuas del periodo 1681-1692 se extienden en sus comentarios, y señalan figuras como Luisa Miranda con su hija y sobrina, Mariana Henríquez con sus tres hermanas y Valeriana de Salinas. Ellas residían en Buenos Aires, el provincial Tomás Donvidas (1676-1677 y 1685-1689) las destaca en el informe que elevó al general, por sus excelentes virtudes: "profesándose públicamente por hijas de Nuestro Padre San Ignacio y consagrándose a Dios con voto de castidad, dando de mano a toda profanidad y vistiéndose del traje humilde de Jesús, honrándose con el nombre de beatas de su Compañía” (Salinas y Folkenand 2015, 61). Cabe insistir en que ellas no profesaban los votos a la Compañía de Jesús, sino que lo hacían ante sí mismas, lo que se llama votos simples y privados.

Luisa Miranda era muy pobre, a pesar de ser hija de un hidalgo militar, se dedicó a atender enfermos hasta amortajarlos y llevaba una vida ascética, al igual que Mariana quien hizo traer de España una imagen de la Concepción, que dejó en el colegio de la Compañía. Las hermanas de Mariana, Catalina, Isabel e Inés Henríquez de Santa Cruz eran herederas de las tierras que pertenecieron a su abuelo español, don Francisco García Romero, cuya estancia superaba los límites actuales del partido de Lomas de Zamora, además de contar con una decena de esclavas y casa en la ciudad (Birocco 2000, 3; Fraschina 2015, 58-59). Su abuelo estuvo casado con la asuncena Mariana González de Santa Cruz, hermana del santo jesuita paraguayo. Las herma-

6 Biblioteca del Colegio del Salvador, Buenos Aires (citado en Furlong 1944, 81). 
nas se dedicaron a educar huérfanas e hicieron votos a nuestra señora del Carmen, culto mariano de gran popularidad entre las mujeres.

Valeriana era natural de La Rioja, se trasladó a Buenos Aires, y falleció antes de cumplir los 18 años de edad, cuando hacía poco se había consagrado a: "Jesús en el estado de beata de su compañía". Huyó de su casa y se refugió en la sacristía de la iglesia de los jesuitas, porque su madre quería casarla con un encomendero de Catamarca. Intervino hasta un alcalde ordinario que la llevó a vivir con una señora beata, pero su madre la secuestró y la justicia, a través del defensor de menores, le quitó la tutela. El caso fue extenso, Valeriana se trasladó a Buenos Aires y en poco menos de un año una fiebre, que la tuvo en cama por tres meses, terminó con su vida (Salinas y Folkenand 2015, 61-64). Además de ellas, Furlong tomó las palabras del doctor Raúl A. Molina, quien fue enfático en señalar a la educadora doña Juana de Saavedra, como fundadora de la Casa de Beatas de Buenos Aires, y a Blanca Godoy, de la de Santa Fe.

En 1692, en el antiguo y abandonado hospital Real de San Martín de Buenos Aires, el gobernador Agustín de Robles, y seguramente por pedido de las beatas, propuso que en el edificio funcionara una casa de recogimiento de huérfanas. Contó con el apoyo del Cabildo y del obispo Azcona Imberto, quien argumentaba que con esa iniciativa se resguardaría la castidad de las jóvenes. Pero poco se hizo, y siete años después ocuparon el edificio refaccionado, aunque para el uso de las beatas y bajo la administración temporal de Pedro de Vera y Aragón, con la conducción espiritual de la viuda doña Juana de Saavedra, beata de la Compañía. Además de residir allí, en la casa se impartía instrucción a niñas y jóvenes de la ciudad, en tanto que un jesuita frecuentaba la capilla para oficiar misa. Pero la corte española desautorizó su funcionamiento, y el flamante gobernador le devolvió al edificio las funciones de hospital, por lo que en 1702 las beatas debieron abandonar la casa. La comunidad religiosa volvió a su hogar, hasta que pudo adquirir una casa que se debió refaccionar considerablemente, con numerosas habitaciones pequeñas y hasta una capilla consagrada a la virgen del Buen Consejo. Se inauguró como casa de ejercicios para mujeres en 1752, y retornó a sus actividades (Furlong y De Paula 1984, 42-43). Para la expulsión, la casa fue abandonada y en 1779 pasó a funcionar la Casa de Niños Expósitos y luego fue cárcel militar, hasta que se demolió (Page 2016, 112). 
Por otra parte, en Santa Fe se destacó la santafecina doña Blanca Godoy, de noble familia española, ${ }^{7}$ que colaboró con el padre Miguel Benavídez, rector del colegio, en la aplicación de los ejercicios para mujeres. Furlong $(1929,39)$ relata su biografía siguiendo el obituario de la carta anua del periodo 1735-1743, y la amplía en su historia del Colegio de Santa Fe (Furlong 1962, 313-320).

Doña Blanca era una señora muy distinguida y de cierta fortuna, quien en 1676 había decidido embarcarse a España y entrar a un convento de monjas. Pero su barco naufragó en el Río de la Plata y regresó a Santa Fe, donde hizo voto de virginidad y vistió el hábito de las beatas de la Compañía de Jesús. A partir de entonces decidió imitar el modo de vivir de los beaterios creados en España por Marina de Escobar, ${ }^{8}$ bajo la dirección espiritual de uno de los sacerdotes. Empleaba su tiempo en socorrer a los pobres y menesterosos, vivía en su casa, heredada de su padre, donde tenía esclavos y una capilla con varias imágenes que era presidida por la de san Ignacio. Solo salía los días festivos por la mañana a la iglesia, o bien a visitar enfermos, y mantenía las mismas distribuciones de los jesuitas. Ella introdujo los ejercicios espirituales en Santa Fe, un año antes de fallecer.

Murió a los 74 años, a fines de diciembre de 1734, y les dejó su casa a los jesuitas. A su funeral asistieron los padres que regresaban de la congregación provincial y pasaban por Santa Fe, junto a otros cinco misioneros destinados al Paraguay. Su catafalco se adornó con inscripciones en versos latinos y castellanos, al final se pronunció una oración fúnebre sobre sus virtudes y méritos (Page 2004, 326-327), y sus restos fueron sepultados en la iglesia de los jesuitas.

En la misma carta anua se menciona a doña Francisca Quinteros, quien había llevado una vida edificante en Córdoba, pero al quedar viuda hizo votos de castidad y vistió el hábito de las beatas en Córdo-

7 Hija de don Antonio Godoy y Ponce de León y de María de Vega y Frías. Su padre nació en Marchena, Andalucía, heredó de sus padres los mayorazgos de Puerta del Rey y Villar Gallegos (Furlong 1962, 317).

8 La vallisoletana y venerable Marina de Escobar (1554-1633) fue una religiosa mística fundadora de la rama hispana de la Orden de Santa Brígida. Sin ser monja, su santidad era reconocida y promocionada entre el pueblo, con revelaciones y apariciones divinas que no agradaban en Roma. Luis de la Puente, exitoso jesuita y escritor asceta, fue su director espiritual y hasta escribió sobre la "vida maravillosa" de esta beata, donde compila sus revelaciones y visiones (Burrieza 2005, 107). 
ba, junto con sus cinco hijas; un hijo varón siguió el sacerdocio. Se ganaban el sustento con sus manos, porque habían quedado pobres. El resto del tiempo lo empleaban en los ejercicios espirituales ayudando al director espiritual; recibieron en su casa a otras mujeres que querían guardarse, como ellas, contra los peligros del mundo y conforme a la ley divina bajo el escudo de la Compañía.

También llevaron las mismas distribuciones que los jesuitas, se levantaban y acostaban a la misma hora, hacían meditaciones, austeridades corporales, examen de conciencia y lectura espiritual diaria. Asistieron caritativamente a los enfermos hasta que las fuerzas de María mermaron debido a una enfermedad grave, y falleció el 5 de febrero de 1737, día de los mártires de Japón. Al día siguiente se celebró su funeral en la iglesia del colegio, y sus restos fueron sepultados bajo el altar de san Francisco Javier (Page 2004, 327-328).

Hay otro documento interesante, conocido de forma genérica como "El libro de consultas del provincial", que si bien solo se conserva del periodo 1731-1747, algo trata sobre ciertas beatas. En 1734 se refiere a una esclava llamada Ana Francisca Javier, que donó doña Juana de Herrera que "esta en lo de las Beatas trabajando siempre para la Iglesia”. En esa reunión se discutió que "se le de racion de carne, i un pan cada dia, i de vestir a sus tiempos, por ser de justicia, y todo fue de parezer de todos los PPCC".?

En otra reunión de consultores de aquel mismo año se permitió: "tomar la sotana de Beata a una pobre exemplar, que lo deseaba, y pretendia muchos años ha”. ${ }^{10}$ En 1738, el provincial convocó a sus consultores y a los padres Colombo y Masala

si se le podría dar entierro a una Beata, que estaba muy mala, y avia estado muchos años en la casa de Exercicios, y assitindo á ellos. Los mas juzgaron, que no convenia, por no ser persona noble; $y$ assi determino su $\mathrm{R}^{\mathrm{a}}$. que en caso $\mathrm{q}^{\mathrm{e}}$. ahora muriesse, $\mathrm{q}^{\mathrm{e}}$ no se le diesse. $^{11}$

9 Archivo General de la Nación. Biblioteca Nacional. Tomo 4. Consultas desde 1731 hasta 1747, Leg. 69, f. 24.

10 Archivo General de la Nación. Biblioteca Nacional. Tomo 4. Consultas desde 1731 hasta 1747, Leg. 69, f. $25 \mathrm{v}$.

11 Archivo General de la Nación. Biblioteca Nacional. Tomo 4. Consultas desde 1731 hasta 1747, Leg. 69, f. 85. 
En la misma sesión, el rector del Colegio Máximo trajo a discusión que

doña Lucia de Herrera ( $q^{\mathrm{e}}$ es noble, y exemplar, y tiene en casa cinco mil ps con animo de dexarlos á casa, con lo demás que tiene) estaba con grande desconsuelo por no tener licencia $\mathrm{p}^{\mathrm{a}}$ enterrarse en casa, como lo avian tenido sus $\mathrm{H}^{\text {as }}$. Todos juzgaron, $\mathrm{q}^{\mathrm{e}}$ con la dha se podía condescender; pues la prohibición de N.P. Gl, y reservacion $\mathrm{p}^{\mathrm{a}}$ conceder sepultura, no se entendía en tal caso, como pareze se respondio en Roma; y su $\mathrm{R}^{\mathrm{a}}$ el P. Prov ${ }^{l}$ dixo, que se enterrase en casa, si hacia el bien, $\mathrm{q}^{\mathrm{e}}$ se decía. ${ }^{12}$

En 1741, y de visita en La Rioja, el provincial convocó a consulta y:

propuso en ella la pretensión de dos Señoras, que deseaban ser beatas, Maria Salazar y Benadivez y Melchora Paiz: á la primera todos juzgaron ser digna, que se le conceda el favor que pide; en la segunda hallaron los mas alguna dificultad, por lo que pareze no es española, y tal vez ni aun quarterona, y por no tener mas que 25 años: con todo esso se dejo licencia al P. Rector que aun esta pudiesse admitir el P. Rector, si hallare que sus CC la juzgaren digna. $^{13}$

De tal manera que si bien cualquier mujer podía ser beata, había diferencias, propias del tiempo en que vivieron. Ellas también consideraban la muerte y su enterramiento como un asunto de suma importancia.

\section{La Casa de las Beatas}

Es fácil verificar en el trabajo de Maeder (2001), que solo en un inventario de las temporalidades figura una "Casa de las Beatas". Si bien se

12 Archivo General de la Nación. Biblioteca Nacional. Tomo 4. Consultas desde 1731 hasta 1747, Leg. 69 , f. 85

13 Archivo General de la Nación. Biblioteca Nacional. Tomo 4. Consultas desde 1731 hasta 1747, Leg. 69, f. 109. 
mencionaron otras, parece ser que para la expulsión ya no quedaban, o bien en su mayoría eran privadas, de mujeres que se hacían llamar beatas o directamente residían en las casas de ejercicios para mujeres como la de Buenos Aires, o de La Rioja que después de la expulsión se propuso para que ahí funcionara el Cabildo, pero terminó en ruinas.

Según el inventario que firma el "maestro arquitecto Joaquín Marín”, el sargento Fabro y el escribano Arrascaeta ${ }^{14}$ la Casa de las Beatas se encontraba en la plazoleta de la iglesia del colegio de Córdoba. Era un inmueble de una planta, de 90 pies $( \pm 27 \mathrm{~m})$ de frente por $30( \pm$ $9 \mathrm{~m}$ ) de fondo, "de cal y piedra buena”. Aunque: “Toda en obra viexa y en partes amenaza ruina”. Tenía un patio y un corralillo, con seis cuartos y una cocina, pero "sin muebles". ${ }^{15}$ El edificio se tasó en 600 pesos; ${ }^{16}$ un tasador especializado describió todos los bienes inmuebles de los jesuitas. Se desconoce el origen de él, aunque se declaraba europeo y activo desde 1750. Trabajó en las obras del fuerte de Buenos Aires, también dirigió la reconstrucción de la casa del gobernador y construyó el santuario de Luján, del arquitecto Masella (1754-1763). Marín hizo un peritaje de las obras de la catedral de Córdoba (1770), y también en la iglesia de la Compañía de Jesús de Potosí (1773). Construyó un puente sobre el río Pilcomayo y, una vez establecido en Sucre, fue designado alarife mayor de la ciudad, además de construir las iglesias de San Juan de Pocoata y San Pedro de Buenavista (De Paula et al. 2006, 145).

El origen de esta propiedad surge de la formación de la plazoleta ubicada frente al templo del colegio de Córdoba, terreno adquirido por los jesuitas a Pedro Gómez de la Cruz en 600 pesos a fines de 1665, a través del padre Simón de Ojeda quien había sido provincial (1658-1663) y al momento era rector del Colegio Máximo. Un año y

14 Martín de Arrascaeta (Vergara, 1734-Córdoba, 1796) se casó en Córdoba, en 1766, con Urbana de Las Casas y Soberón, con quien tuvo ocho hijos. El matrimonio se radicó en Córdoba en 1768 y un año después remató el cargo de escribano público de Cabildo. Arrascaeta ejerció entre 1769 y 1796, sucedió al portugués Antonio Matos de Acevedo en el Registro número 1. En 1789, como escribano, repartió medallas con motivo de la asunción de Carlos IV, también actuó como escribano del Cabildo, en 1792.

15 Archivo Histórico de la Provincia de Córdoba, Leg. 40, Exp. 9, Año 1771, ff. 91-91v. (Este legajo fue sustraído).

16 Para tener una referencia de los valores, el edificio del convictorio se tasó en 40.910 pesos, los libros del colegio en 4.680, los 323 esclavos en 40.910 y la quinta de Santa Ana, con su ganado, en 3.968 (Maeder 2001, 164-166). 
medio después (1667), los jesuitas recibieron en donación, del doctor Ignacio Duarte de Quirós, una fracción colindante que el sacerdote había comprado en 1650, por 250 pesos. El cuarto de manzana otorgado en merced, al tiempo de la fundación, fue de los primeros en dividirse y trasferirse en varias oportunidades. Así, el escribano Diego de Sotomayor dividió el solar y lo entregó en dote a su hijastra María de Castañeda, quien vivió allí con su esposo Francisco Gómez, él le agregó una fracción a su solar (Luque 1980, 60-130). Francisco hizo un testamento a favor de sus hijos Clara, Mariana, Ignacio y Pedro, quien en definitiva se quedó con gran parte del solar y lo vendió a los jesuitas. Duarte de Quirós adquirió la parte de Clara (Page 2008, 240).

Figura 1. Fotografía de la plazoleta de la Compañía, anterior a 1888, donde se aprecia a la izquierda una parte de la antigua Casa de las Beatas

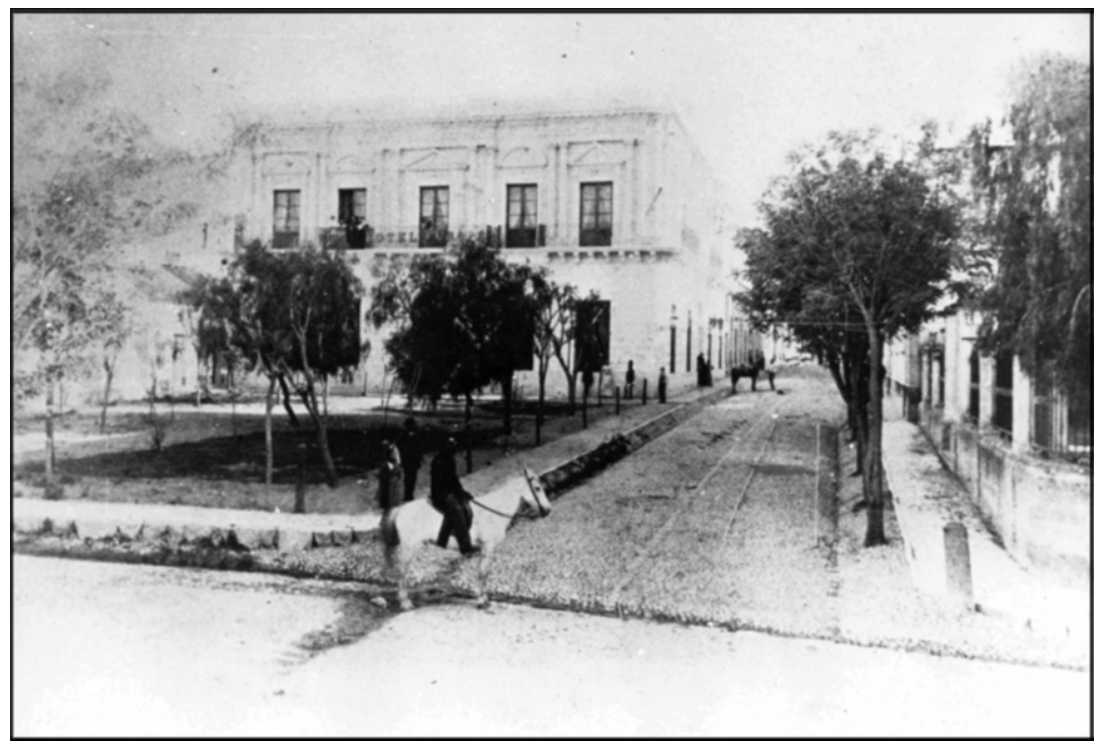

Fuente: Page (2008, 242).

Las dimensiones de los terrenos mencionados no son claras, y se cree que los jesuitas, al adquirir ambos solares, edificaron esos 90 pies de frente a la plazoleta y los 30 de fondo, que constan en el inventario. Se desconoce la fecha y las circunstancias en que se construyó, al 
menos no hay información en cartas anuas, memoriales y cartas de los generales y provinciales que mencionen el asunto directamente, y tampoco el libro de cuentas del colegio es preciso en este punto.

Monseñor Pablo Cabrera $(1934,365)$ conoció el edificio y, además de dar testimonio de ello, escribió que las beatas residían en una casa muy modesta ubicada en la plazoleta, bajo la dirección espiritual de los jesuitas. Su tarea era prestar ayuda para la atención de la casa de los ejercicios, a través de trabajos manuales y colectas para su manutención (véase Figura 1).

En 1724, el historiador sanjuanino, después de recorrer el tedioso libro de cuentas del colegio, mencionó varias cuestiones que encontró referentes al edificio, entre ellas "cañas y madera para la casita de las beatas". También apuntó los nombres de doña Petronila, quien administraba la casa en 1720, y al año siguiente doña María Peredo.

Según el padre Beguiriztain, tanto la Casa de las Beatas como la de ejercicios de mujeres, de Córdoba fueron habilitadas por María Antonia de la Paz y Figueroa. Cabrera (1934) trascribió una relación que le facilitó a Furlong, que dejó el padre expulso Lorenzo Casado, donde cuenta cómo hacían los ejercicios las mujeres: las españolas separadas de las criadas, mulatas, mestizas y negras. "Hechas las listas, va el P. Prefecto con su compañero a la Casa; señala los sitios de las salas y cuartos donde colocan las camas, y se vuelve al Colegio". Sobre el edificio agregó: "Tienen dentro su oratorio muy decente, que solo sirve para tener aquellas distribuciones” (Beguiriztain 1933, 17).

La venta de la Casa de las Beatas, e incluso la plazuela, se trató en la sesión del Cabildo del 3 de octubre de 1776, de acuerdo con lo comunicado por el escribano de la Junta Municipal de Temporalidades en cuanto a la decisión de la Junta Superior (Gracia 1940, 473). Sin embargo la operación se demoró con la llegada, al año siguiente, de María Antonia de la Paz y Figueroa, quien permaneció en la ciudad dos años junto a su sobrina Ramona y cuatro beatas de Santiago (Fraschina 2015, 68). Luego don Cipriano Moyano compró el edificio, en 1782 (Gracia 1940, 533). ${ }^{17}$

Los jesuitas volvieron a ocupar el mismo inmueble que incluía el Colegio de San José, fundado en 1882. A su regreso, la plazoleta siguió

17 Archivo Histórico de la Provincia de Córdoba, Esc. 3, Leg. 8, f. 237. 
siendo de ellos, al punto que el municipio les otorgó varios subsidios, al menos desde 1866, para que la mantuvieran (Page 2008, 241). Más aún, en el terreno de la Casa de las Beatas se ubicó la Asociación Católica Artesanos de San José que, con otra denominación, había fundado el jesuita Cayetano María Carlucci, en 1897.

\section{Los años inmediatos a la expulsión: el legado}

Después de la expulsión se formó otra "casa de beatas" en Catamarca, en el sitio de la huerta de la residencia jesuítica. Allí las hermanas Juana Rosa, Agustina y María Manuela Villagrán levantaron un asilo para niñas huérfanas, en 1776, con los materiales del colegio ignaciano. Fueron apoyadas por las carmelitas de Córdoba y el obispo san Alberto, quien aprobó su instituto, en 1786, y la corona dos años después; solventaban sus gastos con dos estancias donadas por las hermanas (Maeder 2001, 251; Gershani 2015).

En estos años fue relevante la figura de María Antonia de la Paz y Figueroa (Santiago del Estero, 1730-Buenos Aires, 1799); ${ }^{18}$ cuando tenía 15 años se incorporó a las beatas de Santiago del Estero e hizo votos privados, y cambió su nombre por María Antonia de San José, santo dilecto de la Compañía de Jesús. ${ }^{19}$ Furlong recuerda que fray Julián Perdiel, en la oración fúnebre de María Antonia, beata de la Compañía, dijo: que "a los quince años de edad hace votos en presencia de los altares y viste el hábito del gran Ignacio de Loyola, para buscar, como él, la mayor gloria de Dios", y agregó otro documento anónimo: "Va vestida de sotana y manteo largo, como iban los jesuitas", aunque en las misiones los jesuitas no usaban manteo, sí lo hacían en los colegios. Además, va descalza y "lleva siempre una cruz

18 La bibliografía impresa sobre la beata es inmensa, parte del folleto "Il santo zelo d'una americana. Al sesso divoto di Europa” (el estandarte de la mujer fuerte), publicado en 1792 en forma anónima en italiano y luego en varias lenguas. Esta bibliografía llega hasta la obra más completa de Alicia Fraschina (2015), investigación que la autora trabajó al menos por 15 años.

19 A tal punto lo fue para los jesuitas del Paraguay, que cuando Carlos III les prohibió seguir funcionando en Italia con el nombre de provincia del Paraguay, adoptaron el de provincia de San José (Page 2011,47). 
en las manos", como verdaderamente hacían los misioneros con una cruz de poco más de un metro y medio de altura (1947, 367-368).

Mientras Beguiriztain cuenta que su confesor fue Ventura Peralta, llamado en realidad Buenaventura Porcel de Peralta, jesuita salteño que se encontraba en Santiago del Estero para la expulsión, ${ }^{20}$ y murió en Faenza, en 1805 (Storni 1980, 225), quizá fue quien le entregó su manteo, como se señala en el opúsculo de 1792.

Luego de la expulsión, María Antonia le dio difusión especial a la práctica de los ejercicios espirituales, fue autorizada por el obispo de Córdoba, don Juan Manuel Moscoso y Peralta, en 1773, y el de Buenos Aires, fray Sebastián Malvar y Pinto, a pedir limosna para mantener los ejercicios y fundar una casa de recogimiento. Con un grupo de mujeres pasó de Santiago del Estero a Jujuy y de allí a Buenos Aires, a donde arribó en 1779, a su paso fue dejando largas tandas de ejercicios en cada ciudad por la que transitó. Permaneció en la que le fue más hostil, seguramente por influencia del virrey Vértiz, enemigo acérrimo de los jesuitas. A pesar de que el obispo la apoyaba, debía dar los ejercicios en forma restringida hasta que el virrey claudicó, y los porteños pudieron ayudarla económicamente para levantar una casa de ejercicios, cuyo edificio aún se conserva. La Mama Antula, como le decían, fue proclamada beata después de cien años de iniciado el proceso canónico, el 27 de agosto de 2016, por el papa jesuita Francisco, quien estableció la fiesta litúrgica el 7 de marzo, fecha de su muerte.

\section{Conclusiones}

La opción de vida para la religiosidad femenina en tiempos de la Colonia era ingresar a los conventos de monjas, o bien asumir el rol de beatas, aunque en muchos casos esta última era la única alternativa, pues los conventos escaseaban o bien había que aportar una dote considerable para entrar, de la que las beatas estaban exentas porque no dependían de una orden religiosa.

20 En Santiago del Estero se encontraban los padres Juan Nicolás de Araoz como rector, Francisco Almirón, Marcos Avendaño, Luis Colombo, Luis Díaz Caballero, Antonio Morales, Fernando Ordóñez, Buenaventura Porcel de Peralta, Silvestre Rami, Manuel Ribeiro, José Francisco Rodríguez y Francisco Ruiz de Villegas, además de cuatro coadjutores (Page 2011, 117). 
La Compañía de Jesús, sin contar con una rama femenina, les prestó un interés particular a las religiosas, les ofreció sus reglas a las que contaran con una organización mínima, y fueron guías espirituales desde un primer momento en la provincia del Paraguay, con la intervención de Diego de Torres, en Asunción.

Las actividades de las beatas se concentraron en atender enfermos o bien instruir tanto a huérfanas como a quienes no lo eran, pero fundamentalmente en asistir a los jesuitas en la práctica de los ejercicios espirituales para mujeres. Los documentos jesuíticos dan cuenta de ellas, mencionan a varias que participaron en diversas ciudades. Así, los jesuitas contemporáneos destacaron las figuras de Luisa Miranda, las hermanas Henríquez y Juana de Saavedra, en Buenos Aires; Valeriana de Salinas, en La Rioja; Blanca Godoy, en Santa Fe y Francisca Quinteros y Lucía Herrera, en Córdoba, entre otras. Nombres que enriquecen la historia eclesiástica en consonancia con la actividad pastoral de los jesuitas.

Se organizaron en casas privadas, por lo general de alguna dama acaudalada, o bien en las comunitarias que llamaron beaterios, aunque para la expulsión se menciona solo el de Córdoba, que a su vez servía para casa de ejercicios. Se ubicó en una fracción pequeña de terreno, donada a los jesuitas para que tuvieran una plazoleta frente a la iglesia del colegio. El inventario de las temporalidades la describe y le da poco valor, de seguro porque para esa época se encontraba en mal estado, pero siguió funcionando gracias a la participación activa de María Antonia de San José, beata de la Compañía, que ingresó como tal, al beaterio de Santiago del Estero siendo muy joven. Fue una figura trascendental que se abocó a reorganizar la práctica ignaciana después de la expulsión, hizo construir un edificio para ese fin, que aún se conserva. Su vida encontró sentido con los ejercicios de san Ignacio, porque la llevaron a mantener viva la memoria de los jesuitas desterrados y condenados por una pragmática que el monarca Borbón disponía por su real voluntad, aunque fuera precisada con tiempo y minucioso cuidado. 


\section{Archivos}

Archivo General de la Nación. Biblioteca Nacional.

Archivo Histórico de la Provincia de Córdoba.

\section{Bibliografía}

Ambrona, A. G. 2017. Ignacio de Loyola y las mujeres. Benefactoras, jesuitas y fundadoras. Colección Historia. Serie mayor. Madrid: Ediciones Cátedra.

Beguiriztain, J. 1933. Apuntes biográficos y otros documentos referentes a la Sierva de Dios María Antonia de la Paz y Figueroa. Buenos Aires: Talleres Gráficos A. Baiocco y Cía.

Biblioteca del Colegio del Salvador, Buenos Aires. Litteræ Anua Provincia Paraquaria Societatis Jesu ab anno 1682, usquè ad annum 1688. missa ad Reverendum Adm. P. N.Thyrsum Gonzalez Societatis eiusdem Prepositum Generalem.

Birocco, C. M. 2000. La primer casa de recogimiento de huérfanas de Buenos Aires: el beaterio de Pedro de Vera y Aragón (1692-1702). En La política social antes de la política social. Caridad, beneficencia y política social en Buenos Aires, siglos XVII a XX, compilado por J. L. Moreno, 1-21. Buenos Aires: Trama/Prometeo.

Burrieza Sánchez, J. 2005. La percepción jesuítica de la mujer (siglos XVI-XVIII). Investigaciones Históricas. Época Moderna y Contemporánea (25): 85-116.

Cabrera, P. 1934. Cultura y beneficencia durante la Colonia. Irradiación del Colegio Máximo Jesuítico de Córdoba del Tucumán. Revista de la Universidad Nacional de Córdoba 21 (9-10): 351-371.

De Paula, A., R. Gutiérrez y G. M.Viñuales. 2006. Arquitectura hispanoamericana en el Río de la Plata. Diccionario biográfico de sus protagonistas 1527-1825. Buenos Aires: Cedodal. 
Fraschina, A. 2015. La expulsión no fue ausencia. María Antonia de San José, beata de la Compañía de Jesús: biografía y legado. Rosario: Prohistoria Ediciones. Furlong, G. 1962. Historia del Colegio de la Inmaculada de la ciudad de Santa Fe y de sus irradiaciones culturales, espirituales y sociales, 1610-1962, tomo primero 1610-1861. Buenos Aires: Filial Ex Alumnos.

Furlong, G. 1947. Un valioso documento sobre la Madre Antula. Estudios de la Academia del Plata (2): 363-378.

Furlong, G. 1944. Historia del Colegio del Salvador y de sus irradiaciones culturales y espirituales en la ciudad de Buenos Aires 1617-1943, tomo 1, 1617-1841. Buenos Aires: El Colegio del Salvador.

Furlong Cardiff, G. 1929. Glorias santafecinas. Buenaventura Suárez, Francisco Javier Iturri, Cristóbal Altamirano. Estudios biobibliográficos precedidos de una introducción. Buenos Aires: Surgo.

Furlong, G. y A. De Paula. 1984. Manzana de las Luces Colegio “Grande” de San Ignacio 1617-1767. Buenos Aires: Comisión Nacional de la Manzana de las Luces.

Gershani Oviedo, M. 2015. Las beatas Villagrán y las carmelitas en Catamarca. La Unión. http://launiondigital.com.ar/noticias/154925las-beatas-villagran-y-las-carmelitas-catamarca (20 de enero de 2016).

Gracia, J. 1940. Los jesuitas en Córdoba. Buenos Aires: Espasa-Calpe.

Hernández, P. 1913. Misiones del Paraguay. Organización social de las doctrinas guaraníes de la Compañía de Jesús, tomo II. Barcelona: Gustavo Gili.

Huonder, A. 1932. Ignatius von Loyola. Beiträge zu seinen Charakterbild. Colonia: Katholische Tat Verlag.

Lozano, P. 1755. Historia de la Compañía de Jesús de la provincia del Paraguay, tomo segundo. Madrid:Viuda de Manuel Fernández. 
Luque Colombres, C. A. 1980. Orígenes históricos de la propiedad urbana de Córdoba (siglos XVI-XVIII). Córdoba: Universidad Nacional de Córdoba.

Maeder, E. J. A. 2001. Los bienes de los jesuitas. Destino y administración de sus temporalidades en el Río de la Plata 1767-1813. Resistencia: Instituto de Investigaciones Geohistórics (IIGH)- Consejo Nacional de Investigaciones Científicas y Técnicas.

Martínez de la Escalera, J. 2004. Mujeres jesuíticas y mujeres jesuitas. En A Companhia de Jesus na Península Ibérica nos sécs. XVI e XVII: espiritualidade e cultura: actas do Colóquio Internacional. Oporto: Faculdade de Letras da Universidade do Porto, Instituto de Cultura Portuguesa; Universidade do Porto, Centro Inter-universitário de História da Espiritualidade.

Muriel, D. 1919. Historia del Paraguay desde 1747 hasta 1767. Obra latina del P. Domingo Muriel de la Compañía de Jesús traducida al Castellano por el P. Pablo Hernández. Madrid: Librería General de Victoriano Suárez.

Page, C. A. 2016. Las casas de ejercicios de los jesuitas en la antigua provincia del Paraguay. IHS. Antiguos Jesuitas en Iberoamérica 4 (2): 95 120.

Page, C. A. 2011. Relatos desde el exilio. Memorias de los jesuitas expulsos de la antigua provincia del Paraguay. Asunción: Servilibro.

Page, C. A. 2008. El espacio público en las ciudades hispanoamericanas. El caso de Córdoba (Argentina). Siglos XVII y XVIII. Córdoba: Junta Provincial de Historia y Sociedad Chilena de Historia y Geografía.

Page, C. A. 2004. El Colegio Máximo de Córdoba (Argentina) según las cartas anuas de la Compañía de Jesús. Córdoba.

Pons Fuster, F. 1991. Mujeres y espiritualidad: las beatas valencianas del siglo XVII. Revista de Historia Moderna, Anales de la Universidad de Alicante (10): 71-96. 
Rahner, H. 1956. Ignatius von Loyola. Briefwechsel mit Frauen. Friburgo: Verlag Herder.

Rivera Garretas, M. M. 2005. La diferencia sexual en la historia. Valencia: Univesitat de Valencia.

Ruiz Jurado, M. 2001. Congregaciones religiosas: beaterios. En Diccionario histórico de la Compañía de Jesús. Biográfico-temático, compilado por Charles O’Neill y Joaquín Ma. Domínguez, 920-923. Madrid/ Roma: Universidad Pontificia de Comillas/Institutum Historicum.

Salinas, María Laura y Julio Folkenand. 2015. Cartas anuas de la provincia jesuítica del Paraguay 1681-1692. 1689-1692. 1689-1700. Colección Biblioteca de Estudios Paraguayos. Asunción: Centro de Estudios Antropológicos de la Universidad Católica.

Salinas, María Laura, Fernando Pozzaglio y Pedro M. O. Svriz Wucherer. 2008. Cartas anuas de la provincia jesuítica del Paraguay 1650-1652 y 1652-1654. Resistencia: IIGH.

Soto Artuñedo, W. 1997. Ignacio de Loyola y la mujer. Proyección (44): 299-318.

Storni, H. 1980. Catálogo de los jesuitas de la provincia del Paraguay (cuenca del Plata) 1585-1768. Roma: Institutum Historicum S. I. 